\title{
()
}

\section{Educando bebês: representações da infância por sua materialidade no início do século XX}

Educating Babies: Representations of Childhood through Material Elements, in the Early Twentieth-Century

Educar a los bebés: representaciones de la infancia por su materialidad a principios del siglo XX

Carla Oliveira* iD orcid.org/0000-0003-3520-7258

Maria do Carmo Martins** (iD orcid.org/0000-0002-2029-1285

Para citar este artículo: Oliveira, C. y Martins, M. C. (2021). Educando bebês: representações da infância por sua materialidade no início do século xx. Revista Colombiana de Educación, 1(82), 323-346. https://doi. org/10.17227/rce.num82-10808

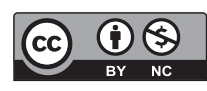

Recibido: 29/11/2019

Evaluado: 20/07/2020

$30 / 07 / 2020$

* Doutorado em andamento pela universidade Estadual de Campinas. Profesora, Universidade Estadual de Campinas: Campinas, São Paulo, BR. Correo: carlaoli@unicamp.br

** Doutorado em Educação pela Universidade Estadual de Campinas; Pós doutorado em Educação (2011) pela Univesity of Brighton- UK; Pós-doutorado em Educação (2018) Universidad Del Valle - CO; Livre Docência em Educação (2018) pela UniversidadeEstadual de Campinas - Unicamp - Brasil.

Correo: carminhapousa@gmail.com 


\begin{abstract}
Resumo
Este artigo aborda a historicidade das práticas educativas da primeira infância no início do século Xx, buscando compreender como objetos voltados ao atendimento dos bebês e as dinâmicas institucionais emergentes no período construíram a educação das crianças pequenas. Partindo da materialidade encontrada no acervo de uma creche centenária na cidade de São Paulo (Brasil), e em diálogo com a historiografia brasileira que aborda a educação da primeira infância, enfatizamos a necessidade de refinar os aportes teóricos-metodológicos para uma história a ser realizada a partir da cultura material infantil. Ao atentarmos para a materialidade da creche, foi possível perceber essa instituição como uma inovação social, que se estrutura em confluência com outros serviços de atendimento à infância do período. Por fim, destacamos as representações sobre as instituições que passaram a compartilhar com as famílias o compromisso de educação e cuidados dos bebês, em consonância aos projetos de desenvolvimento da nação e de futuro social naquele período.
\end{abstract}

\section{Palavras-chave}

História da Educação; educação Infantil; cultura educacional; creches; recursos materiais

\section{Keywords}

Educational history; early childhood education; cultural education; childcare centers; resource materials

\begin{abstract}
This article presents the historicity of early childhood educational practices in the beginning of the twentieth century. The purpose of the study is to understand how baby care items with the emerging institutional dynamics of the period, built education scenarios of young children. Starting from the materiality found in the collection of a nursery in the city of São Paulo, and in dialogue with the Brazilian historiography of early childhood education, we emphasize the need to refine the theoretical methodological approaches to a history to be realized from children's material culture. When the materiality of the nursery was analysed, it was possible to perceive that institution, as a social innovation, is structured in convergence with other childcare services of the time. Lastly, we highlight the representations about some institutions that started to share with families the commitment of baby education and care, in line with the projects of nation development and so-
\end{abstract} cial future at that time.

\section{Resumen}

Este artículo aborda la historicidad de las prácticas educativas de la primera infancia a principios del siglo xx, buscando comprender cómo los objetos centrados en el cuidado de los bebés y la dinámica institucional emergente de la época construyeron la educación de los niños pequeños. A partir de la materialidad encontrada en la colección de una guardería centenaria en la ciudad de São Paulo, y en diálogo con la historiografía brasileña que se ocupa de la educación de la primera infancia, enfatizamos la necesidad de refinar las contribuciones teórico-metodológicas para una historia basada en la cultura material de los niños. Cuando observamos la materialidad de la guardería, fue posible percibir esta última como una innovación social, estructurada en confluencia con otros servicios de cuidado infantil de la época. Finalmente, destacamos las representaciones sobre las instituciones que comenzaron a compartir con las familias el compromiso con la educación y el cuidado de los bebés, alineados con el desarrollo nacional y los proyectos de futuro social en ese periodo.

\section{Palabras clave}

Historia educacional; educación de la primera infancia; educación cultural; guarderías; recursos materiales 


\section{Introdução}

A historicidade dos processos educativos e as representações sobre a infância contidas nas práticas educacionais tem sido tema de interesse dos estudos da história cultural da educação nas últimas décadas, produzindo uma virada metodológica no que diz respeito às pesquisas sobre as instituições educacionais. Temas e recortes temporais voltados à compreensão do cotidiano escolar, seja da ordem pedagógica ou da dinâmica administrativa das escolas, ganharam forte impulso. Destarte, reconhecer a materialidade como elemento essencial na conformação de uma cultura escolar tornou-se fundamental para uma aproximação com práticas do passado como parte da reflexão histórica, pois, como ressaltou Escolano Benito (2017, p. 224), as fontes materiais da escola haviam sido amplamente subestimadas frente aos testemunhos escritos, mas a sua valorização recente supõe um giro epistémico e social importante.

Reconhecendo tal modificação, encontramos em Vidal e Gaspar da Silva (2010), uma análise de como no Brasil esta historiografía modificou o trabalho com as fontes de pesquisas, ressaltando uma tendência em produzir uma história da materialidade, porém em caráter limitado para a produção histórica da educação. Gaspar da Silva e Souza (2015), em estudo comparado sobre a escola primária no Brasil, destacaram o encontro com um grande volume de dados sobre provimentos escolares, além de variado repertório sobre sua materilidade. Entretanto, ressaltam que persistem as dificuldades para refinar os procedimentos teóricos e metodológicos das pesquisas devido ao polissêmico uso conceitual de cultura material, à diversidade de procedimentos com os registros sobre esta materialidade e, a multiplicidade de fontes, arquivos e objetos.

Tais desafios para a pesquisa ampliam-se quando o enfoque passa a ser a educação das crianças bem pequenas, especialmente as atendidas nas creches e escolas maternais. Este artigo vale-se da materialidade disponível no acervo de uma creche centenária, ainda ativa na cidade de São Paulo, visando problematizar as práticas educativas da infância, tanto naquilo que ela apresenta de peculiar, quanto no que a torna representativa do atendimento às crianças pequenas em período no qual as creches são criadas e socialmente legitimadas. Busca-se apontar como objetos e dinâmicas institucionais configuram a educação das crianças pequenas que, em períodos históricos anteriores estiveram majoritariamente sob cuidados familiares, visando seu pertencimento às instituições educativas extra-familiares.

Tal reflexão é necessária tendo em vista a tradição acadêmica que dicotomiza o atendimento em creches à lógica da assistência social e, sua passagem lenta e paulatina ao sistema educacional, definida por processos 
jurídicos-políticos do final do século xx. Esta tradição produziu certa invisibilidade em relação às práticas e atuação das instituições antigas cujo atendimento era destinado a tal etapa da vida da criança.

Neste sentido, os arquivos, os mobiliários e outros utensílios da "Creche Baroneza de Limeira", situada no município de São Paulo, fundada em 1911, possibilitam-nos construir uma narrativa histórica que tem por base a conexão entre educação e infância, em um contexto social no qual essa instituição emergia como uma inovação social para abrigo e assistência às crianças pobres, por vezes adoentadas e cujas familias requeriam atendimento específico para cuidar e educar suas filhas e filhos.

Destaca-se que a creche despontou como instituição especializada no atendimento às crianças pequenas em um cenário político e econômico de grandes mudanças na história brasileira, após a proclamação da República no final do século xıx. A cidade São Paulo, que a sedia, buscava, naquele momento, ancorar seu desenvolvimento social em modelos europeus de civilização, enfrentando, porém, problemas decorrentes de um acelerado processo de urbanização.

A creche foi construída e administrada por Paulina de Souza Queiróz, fundadora da Sociedade Feminina de Puericultura na cidade de São Paulo e descendente direta dos Barões de Limeira. A escolha do nome da creche é uma homenagem à sua mãe. Oriunda de família abastada, proprietária de grande número de fazendas que originaram vários bairros de São Paulo, sua família era também influente politicamente, pois o Barão de Limeira exercera o cargo de vereador na cidade. Assim, ressaltamos que a creche em questão não é apenas exemplar dessa inovação social de atendimento à infância, mas evoca valores e modelos educativos próprios dos sujeitos que estavam, naquele momento, ligados às decisões políticas e que eram influentes econômica e socialmente.

A instituição fundada por Paulina não era congregacional religiosa, entretanto sua vinculação com a religião se expressa em inúmeros objetos, fotografías e documentos encontrados na creche. A relação entre cuidado, educação e formação moral cristã católica estão em consonância com o alerta de Sanglard (2016) ao apontarem a filantropia como uma prática renovadora do período, diferenciando-se das demais práticas de caridade e, ao localizarem seu surgimento atrelado aos preceitos da ciência e ao desenvolvimento social em confrontos com as mazelas sociais. No caso da Creche Baroneza de Limeira (CBL), os dois termos, caridade e filantropia, aparecem nos documentos, indicando, possivelmente, que tal separação não ocorreu de maneira brusca mas que as ações marcadas por ambas concepções de atendimento caminharam juntas nas práticas da creche. 
O artigo divide-se em três partes: na primeira delas, aborda a materialidade como um dos elementos constitutivos da história cultural da educação, na segunda parte, com a descrição dos objetos e suas análises são referenciadas representações das práticas nas creches no Brasil, a partir da materialidade específica da Creche Baroneza de Limeira, contextualizando a instituição que nos permitiu acessar a maior parte do documentos. Na terceira parte, em considerações finais discorre-se sobre o atendimento à pequena infância, estabelecendo aportes teóricos-metodológicos para uma história da primeira infância no Brasil e sua materilidade.

\section{Sobre metodologias e a pesquisa em construção}

O encontro com a instituição ocorreu a partir de uma propaganda de jornal datada de 1921, disponível nos arquivos digitais da Biblioteca Nacional do Brasil que destacava a creche Baroneza de Limeira como usuária de um determinado tipo de "farinha fortificante" na alimentação dos bebês atendidos no local, elemento alardeado como contribuinte para melhoria de suas condições de saúde. Após nos certificarmos que a instituição continuava em atividade, foi realizado um primeiro contato com seus dirigentes que asseguraram a realização da consulta aos seus acervos para a realização da pesquisa.

A creche dispõe de uma série de documentos, utensílios e mobiliários que ao serem analisados, possibilitaram uma aproximação com práticas e representações da infância ali atendida no início do século xx. Os materiais encontrados estavam guardados em armários, alguns mobiliários antigos dispostos em meio a outros utensílios contemporâneos de uso cotidiando, além de identificarmos no prédio um pequeno museu com objetos da creche. Documentos e objetos foram percebidos como um sítio arqueológico para a investigação, permitindo um diálogo com a proposta de Escolano Benito (2017), ao mobilizar o conceito de arqueologia para tratar da memória de instituições escolares. O autor argumenta que os vestigios materiais do passado de uma instituição educativa, assim como restos de um sítio arqueológico, carregam consigo todo um manejo institucional e um valor narrativo próprio atribuído pelos sujeitos que compuseram tal cenário. O testemunho deixado por tais vestígios materiais emergem como elementos da "caixa-preta" da instituição educativa, possibilitando ao investigador do presente a aproximação com as práticas de um tempo que conformaram, tanto representações de uma época, quanto fizeram parte dos processos se socialização e subjetivação dos sujeitos que ali viveram. 
As fontes materiais encontradas na creche foram organizadas da seguinte forma:

\section{Quadro 1.}

Organização das fontes encontradas na Creche Baroneza de Limeira

\begin{tabular}{ll}
\hline 1. Série de Fotografias: & $\begin{array}{l}\text { 1. Fotografias de crianças (posadas ou livres); } \\
\text { 2. Fotografias de adultos (posadas). }\end{array}$ \\
\hline $\begin{array}{l}\text { 2. Série de Objetos/ } \\
\text { Mobiliários: }\end{array}$ & $\begin{array}{l}\text { 1. Uso adulto } \\
\text { 2. Uso infantil }\end{array}$ \\
\hline 3. Série Documental: & 1. Administrativos (listas de materiais, \\
& fichas de matrículas, relatórios) \\
\hline
\end{tabular}

Fuente: Elaboração Própria.

No que corresponde a série de fotografias, a creche dispunha de nove álbuns que englobavam um longo período de seu funcionamento. O mais recente deles data do ano de 2005. As imagens que aparentam ser mais antigas, referentes ao período estudado (de 1911 a 1936) não continham nenhuma datação ou informação sobre autoria. Para realizar as análises foi preciso estabelecer relação com outras fontes, como as atas de reuniões e relatórios. Assim, estima-se que as imagens antigas aqui utilizadas foram produzidas na década de 1930. A reflexão sobre o material iconográfico foi realizada à luz de autores como Burke (2004), especialmente quando faz uso da expressão "fotografia documental", alertando para a importância da contextualização da produção, que deveria considerar desde a identidade do fotógrafo, as pessoas envolvidas, o lugar, entre outros e, também, de Le Goff (1990) que, ao considerar, simultaneamente a fotografía como imagem/documento e imagem/monumento, colabora tanto para a discussão da imagen como o registro material do pasado, quanto como uma espécie de símbolo eleito para representá-lo no futuro.

Objetos e mobiliários foram vistoriados e descritos, mas na pesquisa foram realizados registros fotográficos destes objetos. Sobre eles tampouco foram encontrados muitos dados de procedência, mas em alguns caso, foi possível identificar elementos de fabricação graças a pequenos sinais deixados no objeto. Já a série documental trouxe informações mais completas como data, autoria e descrição de atividades. Contudo, como a ênfase na materialidade desponta como objeto principal, os documentos escritos foram interpretados sempre na busca do diálogo com as fontes materiais de maneira a construir significados e representações sobre tais materiais.

O recorte temporal destacou os anos entre 1911, quando a creche foi inaugurada, a 1936, quando D. Paulina faleceu. Após sua morte, os relatórios passaram a ser publicados em outro formato, diferente do original 
elaborado pela fundadora da instituição. Elaborados em forma de livretos, em tamanho aproximado de $15 \mathrm{~cm} \times 21 \mathrm{~cm}$, contendo em média 20 páginas, os impressos prestavam contas às sócias contribuintes ou àqueles que, de alguma forma, colaboravam para a manutenção da creche, fosse com doações de alimentos, materiais ou recursos financeiros. De maneira geral, destacavam o número de matrículas das crianças, situação sanitária do local e questões relativas à administração, como por exemplo, a chegada das irmãs de caridade em 1914. O apelo à caridade também permeava a escrita dos relatórios, colocando sempre a importância das sócias (damas da sociedade paulista) continuarem a contribuir com a obra social. Há ainda, listas com a descrição dos donativos recebidos.

\section{A educação infantil pelas coisas e objetos}

Como já referenciado, as abordagens sobre a cultura material na historiografía educativa têm possibilitado um novo olhar sobre as práticas na educação, embora, predominantemente, naquela realizada em instituições escolares. Entretanto, mesmo que a educação infantil deva ser compreendida em suas distinções quanto ao modelo escolar, considera-se pertinente reconhecer a grande quantidade de artigos produzidos sobre bebês e crianças pequenas desde o início do século xIx ${ }^{1}$. Além disso, a ampliação das instituições de acolhimento, cuidados e aplicação de principios pedagógicos para crianças menores, a materialidade encontrada em distintos espaços educativos voltados à tal finalidade, assim como suas possíveis aplicabilidades na conformação do sujeito infantil, merecem uma mirada particular.

Kuhlmann Jr. (2001), em estudos sobre a origem das creches no Brasil, aponta para a relação existente entre os preceitos educacionais unidos às questões assistencialistas à camada da população inicialmente atendida pelas creches, refletindo sobre a "interação de tempos, influências e temas" que culminam no surgimento de tal instituição. Deste modo, convém ressaltar que não são todos os elementos escolares que estão presentes quando

1 A Educação Infantil no Brasil compõe a Educação Básica desde 1996, com a promulgação da Lei de Diretrizes e Bases Nacionais (LDBN 9394/96) sendo dividida entre creche (0 a 3 anos) e pré-escola (4 a 6 anos). Em 2009, a Emenda Constitucional 59/2009 determinou que as crianças a partir de 4 anos tivessem sua matrícula obrigatória na Educação Infantil e antecipou o ingresso delas no Ensino Fundamental posibilitando a matrícula de crianças de 6 anos (incompletos). As modificações na legislação referendaram diferentes modelos prescritivos de atendimento a esta faixa etária. Com a Base Nacional Comum Curricular (2018), a educação infantil "vincula educar e cuidar, entendendo o cuidado como algo indissociável do proceso educativo. Neste contexo, as creches e pré-escolas, ao acolher as vivências e os conhecimentos construídos pelas crianças no ambiente da familia e no contexto de sua comunidade, e articula-los em suas propostas pedagógicas, têm o objetivo de ampliar o universo de experiências, conhecimentos e habilidades destas crianças" (BNCC, 2018, p. 36). Assume-se que a E. I. é uma etapa educativa relacionada às experiências e práticas culturais diversas, mas não escolares. 
se pensa no conjunto de objetos e expressões mobilizadas na organização da educação das crianças bem pequeñas mas, ressalta-se que determinadas lógicas institucionais nos permitem perceber a especificidade dessa fase de educação e até mesmo a permeabilidade dela com as dinâmicas escolares na luta em defesa da creche como etapa da educação formal.

A materialidade torna-se elemento presente na discussão quando analisamos as imagens abaixo. A primeira delas, a reprodução de uma foto encontrada nos arquivos da creche.

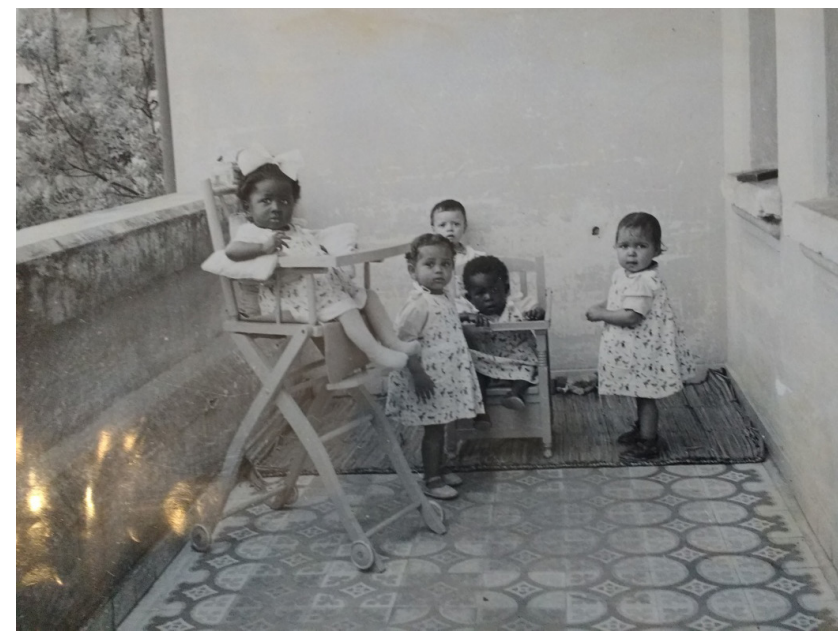

Imagem 1: Série 1 - Fotografias. Tipo: 1.1 crianças

Fonte: Arquivos CBL, S/d. Período estimado: década de 1930.

Nela vemos cinco bebês. Três deles já estão em pé, apresentando alguma capacidade de locomoverem-se com maior independência. Os outros dois, sentados em cadeiras específicas produzidas para bebês: uma delas mais alta, assemelhada às cadeiras usadas para alimentação e a outra em tamanho menor, cuja altura dos pés e do espaldar é adequada e condizente ao tamanho das crianças que estão em pé na foto. Chama a atenção o fato de em ambas as cadeiras, as crianças não terem autonomia para descer ou soltarem-se das barreiras que as mantinham presas nelas. Ao fundo do corredor onde a fotografia foi tirada, vemos uma esteira de palha e sobre ela, uma boneca. As crianças estão com vestimentas iguais e, a que está em primeiro plano, sentada na cadeira alta, está usando uma meia-calça sem sapatos, evidenciando sua distância em relação ao piso e o fato de não possuir autonomia para sair andando naquele espaço. Uma fotografia possivelmente posada, pois as crianças e o cenário estão muito organizados e harmonizados na imagem. O que essa fotografia poderia nos indicar? Uma tentativa de demonstrar o trabalho da creche, em especial, quão 
bem cuidadas e saudáveis elas estavam? Um processo de uniformização da infância na instituição? Provavelmente sim, pois os livros de matrículas da creche indicavam que, a maioria das crianças ingressava na instituição com baixo peso ou alguma condição de enfermidade, o que destoaria desta imagem. Contudo, o que mais importa é o fato de que a preparação do ambiente para a fotografia indica uma intencionalidade e uma concepção de organização das atividades exercidas naquela creche.

O fato de as crianças serem bem pequenas e estarem sozinhas nesta imagem, separadas de crianças maiores e dos adultos; o fato haver destaque ao mobiliário específico para tal faixa etária juntamente com brinquedo e as vestimentas ajustadas ao tamanho e ao conforto dos bebês, indicam o caráter educativo daquela instituição: a higiene, a ordem, as proporções entre objetos, espaços e sujeitos, assim como a ênfase dada à uniformização dos bebês. O caráter multiétnico indica a forma como a instituição preferia ser vista e como ela estava referenciando socialmente o cuidado e suas expectativas em relação à infância. Uma vez que a organização do cotidiano também pode ser visualizada nestas imagens, de uma forma distinta daquelas encontradas em relatos e em medidas prescritivas, emerge por esta fotografia a caracterização de cuidados e assistências à infância como um projeto social e estético.

Outro exemplo é o berço que foi encontrado na creche, em umas das representações museais dos objetos significativos da instituição. Trata-se de um berço de ferro, que já não dispunha de seu colchão, mas que continha um travesseiro em seu interior, figurando os antigos colchões. Tal como aparece na fotografia, ele foi encontrado no espaço da capela, que se encontra dentro do prédio da creche.

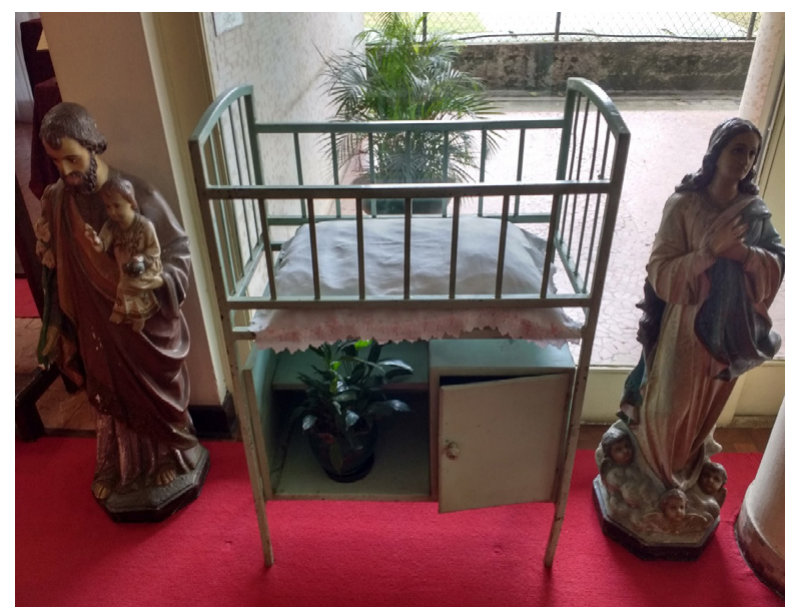

Imagem 2: Série 2. Objetos/Mobiliários. Tipo: 2.2 Mobiliário de uso infantil (berço)Acervo CBL, fotografia pessoal

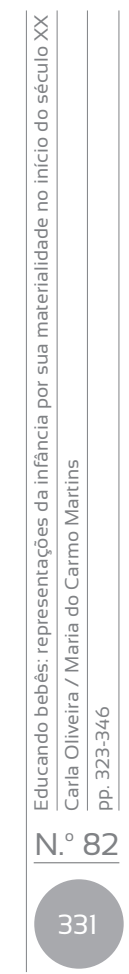


Do ponto de vista expositivo, a fotografia do berço encontrado na atualidade da creche possibilita ao expectador visualizar o cenário que foi cuidadosamente preparado para sua exposição. O berço no centro, ladeado por duas grandes imagens católicas: de São José com o menino Jesus nos braços e, a Nossa Senhora da Conceição, parecem reproduzir um minipresépio, no qual a manjedoura foi substituida pelo berço. Neste caso, não apenas a presença católica da instituição está marcada na representação do minipresépio, como a concepção de uma infância a ser protegida, cuidada e amada se mostram presentes.

Por seu tamanho, o berço fotografado foi provavelmente confeccionado para o uso de recém-nascidos. A fabricação em ferro poderia indicar uma preocupação com a higiene e sua durabilidade, além da resistência do material em uso cotidiano. Em sua configuração como objeto, vê-se que o berço foi fabricado com uma parte anexa, na qual se encontra uma prateleira e um armário com porta. É possível inferir que cada berço fosse designado a uma criança específica e que os objetos destinados a ela, poderiam ser alojados no armário e na estante sob cada estrado.

Sua conformação, entretanto, não é completamente original para a creche, já que as fotografias de outros ambientes como maternidades, hospitais e orfanatos, também apresentam berços parecidos a estes. Tal semelhança indica a circulação de saberes sobre os cuidados com a infância e a apropriação que cada local fez de seus usos. Se a creche compunha a gama de instituições sociais preocupadas com a mortalidade infantil, as doenças da época e fazendo cumprir os preceitos higienistas, percebe-se que seu mobiliário era voltado diretamente aos cuidados com os bebês e, que elas estiveram sob influência de instituições precursoras destas funções sociais, como os asilos e hospitais.

À tríade saúde, higiene e assistência apresentam indicativos de um modelo educativo para as crianças pequenas. Consideramos que os materais e suas finalidades, nos têm permitido ir além dos aspectos sanitários já tão destacados, quando se trata do saber sobre a infância, com foco na criança pobre. Nesse aspecto, Kuhlmann Jr., ao cunhar o termo "educacional assistencialista" (2000, p. 8) refere-se às instituições de educação infantil do início do século xx (creches e escolas maternais), apontando para o fato de que a questão educativa estava diretamente relacionada ao modelo social do período, já que, a partir do modelo eurocêntrico, tais locais de atendimento compunham a gama de instituições sociais necessárias a uma sociedade civilizada, promotoras da "pedagogia da submissão", fazendo com que a população atendida aceitasse sua condição social de pobreza e exploração.

Em sua origen, a creche define-se de maneira diferente daquilo que é possível observar na atualidade e com outro conjunto de objetos, práticas e discursos. Escolano Benito (2017) nos alerta que os objetos do passado 
foram modernos ao seu tempo e inventaram modos culturais com incipientes futuros possíveis. Tal premissa contribuiu para que, ao olhar as fontes de pesquisa pertencentes ao início do século xx, fosse possível pensar em quão inovador seria, por exemplo, a utilização de frascos de mamadeiras de vidro, utilizadas na alimentação das crianças.

Em um período em que os bebês morriam por doenças desencadeadas, por exemplo, pelo mau armazenamento do leite artificial, a esterilização de frascos, juntamente com o processo de fervura do leite, além de inovador, salvava as crianças da morte. O vidro se integrava também à discussão sobre o tipo ideal de alimento preconizado pelos médicos higienistas do início do século, cuja discussão centrava-se na importância do aleitamento materno, na crítica à "amamentação mercenária", realizada por amas de leite, e na importância da esterilização do leite artificial (Sanglard, 2016).

$\mathrm{Na}$ creche Baroneza de Limeira, foram encontradas fotografías e objetos que denotam o esforço em cuidar do aspecto alimentar das crianças. Um deles é a mamadeira que se encontra no museu da creche. Da marca Pyrex, da Companhia Vidraria Santa Marina, o exemplar abaixo pode ser datado dos anos 1950. Sua presença no museu, porém, não corresponde exclusivamente ao fato de, na creche, possivelmente ter sido adotado como instrumento massivo para amamentação dos bebês, mas ao fato de que a mamadeira de vidro possibilitou a continuidade das atividades da creche que, em determinado período, utilizava o artefato em complementação ao trabalho das amas de leite.

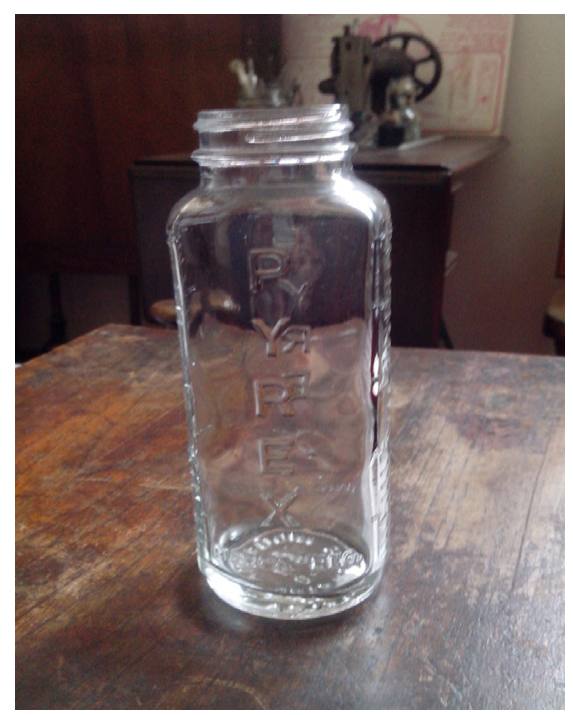

Imagem 3: Série 2. Objetos/Mobiliários. Tipo: 2.2. Objetos de uso infantil (mamadeira de vidro. Fonte: Acervo CBL, fotografia pessoal. 
A atuação das amas de leite é referenciada pela primeira vez no relatório que compreende aos anos de 1912 a 1915, relatando o número de quatro amas, alimentando seu próprio filho mais um bebê da creche. Complementar à amamentação, o leite esterelizado e as farinhas forneceriam os nutrientes para a saúde dos bebês.

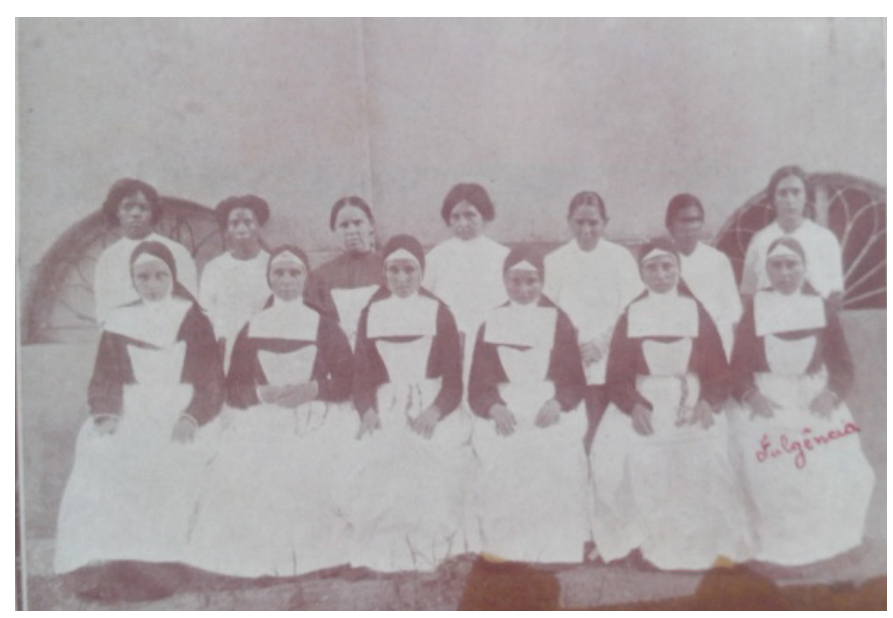

Imagem 4: Série 1. Fotografias. Tipo: 1.2. Irmãs da Congregação da Imaculada Conceição sentadas à frente e, ao fundo, em pé, as amas de leite

Fonte: Acervo CBL, Relatório de Atendimento de 1912 a 1915)

O crescimento do uso das mamadeiras no início do século xx, em especial nas décadas de 1920 e 1930, ocorreu em consonância com o crescimento industrial do leite em pó como destacam Bosi e Machado (2005), e precisa ser entendido no contexto de práticas que profissionais da sáude adotaram, no momento em que essa indústria alimentícia focava parte de suas ações de marketing na agência destes profissionais. Nos arquivos da creche, há o registro do início da utilização do leite em pó exatamente nesta época, pelo serviço Gotta de Leite, trabalho que ocorria em um espaço anexo à Creche, compondo o conjunto de atendimentos e cuidados oferecidos pela instituição. Segundo relatório que compreende os anos de 1927 a 1931, o leite em pó, chamado de "leite seco" começava a ser manejado e fornecido às famílias atendidas "acompanhando os preceitos da nova escola de pediatria" (p. 5). Apesar de não serem encontrados registros fotográficos dos bebês sendo amamentados, percebe-se a presença de saberes profissionais abordando outras vertentes de atendimento à infancia, fato que ilustra a circulação de ideias e práticas, favoráveis às mudanças alimentares no tratos dos bebês. A fotografía, contudo, aponta que os cuidados das crianças eram realizados pelas amas de leite em compartilhamento com as irmãs de caridade. 
As listas de donativos à creche mostram que as mamadeiras eram cada vez mais utilizadas, já que há o registro de doações mensais de vidros de mamadeiras, bem como de artigos de borracha da empresa de manufatura "Progresso", doando rodelas necessárias para a esterilização dos frascos. Embora não haja um registro informando o fim do trabalho das amas, é também, a partir da década de 1930 que não se aborda mais a contratação ou atuação delas dentro da creche.

Por outro lado, outro utensílio, também de uso infantil, um prato de porcelana com desenhos que remetem às cantigas infantis européias, carrega em si uma representação de uma infância que, para além dos cuidados básicos, brinca, canta e possui características próprias que seriam valorizadas por uma ação educativa dentro da creche. Mais uma vez, educação e assistência emergem nos objetos que materializam práticas e representações de uma infância institucionalizada naquele ambiente.

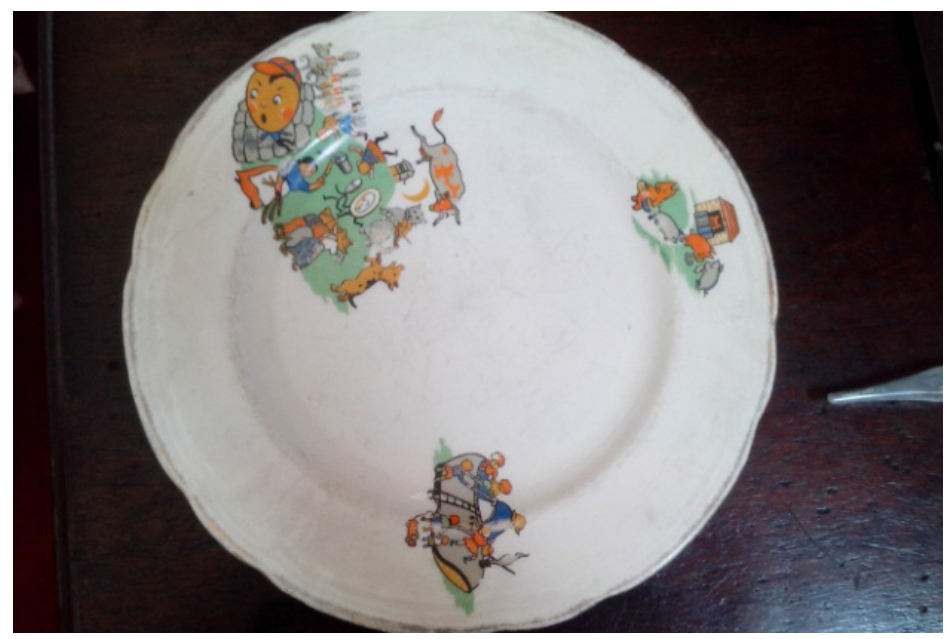

Imagem 5: Série 2. Objetos/Mobiliários. Tipo: 2.2. Objetos de uso infantil (prato em porcelana.

Fonte: Acervo cBL, S/D. Fotografia pessoal

A empresa inglesa Alfred Meakin produziu uma coleção de porcelanas com motivos infantis cujos desenhos eram inspirados em rimas/ músicas infantis tradicionais denominadas "nursery rhymes". No exemplar encontrado dentro do museu da CBL foi possível identificar que uma das ilustrações do prato mostra um sapato com uma mulher dentro e várias crianças à sua volta, indicando se tratar de uma das rimas populares inglesas que têm nos séculos XVI e XVII os períodos prováveis de sua criação: 
There was an old woman who lived in a shoe.

She had so many children, she didn't know what to do.

She gave them some broth without any bread;

And whipped them all soundly and put them to bed $^{2}$.

Nos documentos da creche, não há nada que indique que este exemplar de cerâmica inglesa era utilizada diariamente para alimentar as crianças. Nos livros encontramos referências de doações de "tijelas de louça", pratos e canecas, sempre em grande quantidade (uma única doação forneceu 100 pratos!). Entretanto, a presença deste prato com motivos infantis entre os objetos preservados na creche denota que naquele ambiente, a existência de utensílios com tamanhos proporcionais aos bebês fez parte da concepção de objetos destinados à infância, assim como percebe-se a preservação de objetos para uma representação da infância. Esta infância é dos brinquedos, das historietas, das cantigas que narram a existência de adultos cuidadores e crianças bem cuidadas, obedientes, nutridas e aparentemente disciplinadas.

\section{O surgimento da creche e a relação com a cidade}

O conjunto de ideias de uma criança bem cuidada, saudável e com perspectivas de bem viver representa um modelo ideal de infância. Entretanto, a construção deste modelo esteve calcada em fortes críticas à pobreza e as formas populares e familiares de tratamento à infância. Oliveira (2014) destaca que no jornal "A mãi de família", que circulou ao final do século XIX, o editor, Dr. Carlos Costa, orientava as leitoras sobre um modelo para se tornarem boas mães e visava também, com esta ação, a disseminação do conhecimento para mães das camadas populares, especialmente, as escravas. No periódico, a criação de creches no Brasil emergia da necessidade de abrigar crianças nascidas após promulgação da Lei do Ventre Livre ${ }^{3}$.

A proclamação da República, os processos de industrialização e urbanização trouxeram às grandes cidades uma série de questões sociais. Dentre elas, a elevada taxa de mortalidade infantil despontava como um grande problema. O Boletim Mensal de Estatística Demographo-Sanitária da cidade de São Paulo de janeiro de 1895, por exemplo, indicava 524

2 Havia uma velha mulher que morava em um sapato.

Ela tinha tantas crianças, ela não sabia o que fazer.

Ela deu-Ihes um pouco de caldo sem nenhum pão;

E chicoteou todos eles e os colocou na cama. (Tradução realizada pelas autoras).

3 A Lei do Ventre Livre (Lei imperial n²040), promulgada em 1871, estabelecia, entre outras coisas, que os filhos dos escravos nascidos no Brasil, a partir daquela data, seriam considerados livres e deveriam permanecer junto aos senhores de suas mães, até completarem 8 anos. 
nascimentos e 135 óbitos de bebês até 1 ano de idade ${ }^{4}$. Os números chamavam a atenção dos médicos que tinham forte influência social e eram responsáveis pela disseminação das ideias higienistas que demarcavam o saber científico do período, originando uma série de práticas culturais e atuações sociais junto às diversas camadas da população. Sanglard (2016) em estudo sobre o Rio de Janeiro, destaca a emergência da chamada "questão social", na qual a habitação e a forma de vida das camadas pobres constituiam fontes de preocupações entre as elites e, também, para o poder público, majoritariamente composto por representantes destas elites.

Cuidar das crianças abandonadas fazia-se crucial, corroborando um projeto de sociedade que assombrava-se pelo risco da pobreza, a chegada de imigrantes, e pela presença social dos negros libertos. Chalhoub (1986) destacou que havia um universo ideológico que dividia a sociedade em dois mundos distintos: o mundo do trabalho e o mundo da ociosidade e do crime. Para este segundo, a classe dominante deveria reprimir e controlar para estabelecer a ordem e a moral social.

No caso das crianças pequenas, a creche poderia ser uma das alternativas contra o abandono e a mortalidade. O oferecimento de um abrigo para bebês também poderia contribuir para a diminuição da prática de abandono nas rodas dos expostos. A criação de instituições destinadas a atender a infância desvalida, unia o saber médico com a filantropia e conformava, aos poucos, um modelo institucional de atendimento. Freire (2016) destaca que um dos problemas da infância era representado pela exorbitante taxa de mortalidade infantil, atribuída à alimentação inadequada e em decorrência, às moléstias intestinais. Foi neste cenário que a Creche Baroneza de Limeira começou a atuar, inicialmente, em complementação ao serviço de distribuição de leite e da Policlínica da cidade ${ }^{5}$.

No primeiro ano de seu funcionamento (1911), a creche já contava com o número de 63 bebês atendidos. Os livros de matrícula das crianças dispunham de informações como nome, filiação, nacionalidade, idade, peso, valores pagos pela família ${ }^{6}$.

4 De acordo com Camargo (2012), o período de compreedeu a Primeira República (1889-1930) contou com a forte atuação de médicos que, ocupando cargos em instituições que disseminavam as ideias higienistas e sanitárias, trabalhavam a partir de dados estatísticos, divulgando informações oficiais sobre as condições sanitárias das cidades.

5 O serviço de distribuição de leite, denominado "Gotta de Leite" e a Policlínica foram criados no Brasil a partir do modelo europeu destas duas modalidades de assistência à população. Em São Paulo, surgem em 1905, seguindo um formato de atendimento que já existía no Rio de Janeiro. Enquanto a Gotta de Leite fornecia o alimento fervido e armazenado em frascos de vidros esterilizados às crianças pobres, a Policlínica contava com uma equipe médica que realizava consultas e orientações à mulher gestante e ao bebê. Em 1911, a creche Baroneza de Limeira passa a fazer parte destes serviços.

6 De acordo com os registros, algumas famílias pagavam mensalidades, de acordo com suas condições e posses para manter seus filhos na creche. 
Tais dados estavam atrelados ao modelo de atendimento originalmente pretendido pela creche. Na filiação, por exemplo, aparece sempre o nome de um responsável pela criança, sendo a maioria, nomes de mulheres. De acordo com o primeiro estatuto da creche, seu objetivo principal seria atender crianças, filhas de mulheres trabalhadoras. Já quando o nome principal que aparecia na filiação era o do pai, este havia ficado viúvo e o filho ou filha, ficaria na instituição em regime de internato. Os valores pagos mensalmente também eram relatados nas fichas e havia uma análise sobre as condições de cada um na tentativa de definir um valor possível para pagamento. Registra-se que algumas das famílias não pagavam, devido às precárias condições socioeconômicas.

Dentre os dados que discorriam sobre a questão física da criança, o peso seria uma das informações essenciais. Assim, a ficha destacava o peso na ocasião de sua entrada e o peso da criança no dia da saída. Chama a atenção o curto tempo entre o intervalo de ingresso e de saída da criança na creche, dado que é observado também nas atas mensais de reuniões que trazem informações sobre a alta rotatividade de crianças. Essa questão possibilita pensar que, apesar da instituição ter como objetivo originário o atendimento às crianças durante o dia, para que suas mães pudessem trabalhar, de fato, as demandas emergenciais da cidade com relação à pobreza e as péssimas condições de saúde das crianças, acabaram por modificar o objetivo central da creche, que era utilizada muito mais em situações emergenciais, ou seja, as crianças chegavam já adoentadas, ficavam para serem alimentadas, cuidadas e terem o atendimento médico e, ao ganhar peso e se recuperarem, saíam da instituição. O registro de óbitos, também informados nas fichas, eram recorrentes.

Outro ponto importante presente nos materiais refere-se ao fato de que, muitas daquelas crianças que não deixavam a creche em pouco tempo, serem deixadas para viverem na instituição. A palavra "internato" presente no livro de matrícula impresso especialmente para a creche indica que as crianças residiam no local. As atas das primeiras reuniões indicavam dois tipos de atendimento: o internato, cujas crianças permaneciam na creche durante a semana toda, e passavam os finais de semana com as famílias e, o externato para crianças cujas mães deixavam os filhos pela manhã para irem trabalhar e buscavam ao final do dia. $\mathrm{O}$ segundo modelo de trabalho logo foi extinto por falta de demanda, já que, apesar da concepção originária da creche visar atendemento aos filhos de mulheres trabalhadoras, a real necessidade do período ainda estava no acolhimento às crianças pobres que possivelmente seriam abandonadas por seus responsáveis se não tivessem a creche como abrigo. 
Em outra vertente de trabalho, a creche, inicialmente instalada junto à policlínica realizava atendimentos clínicos e até laboratoriais. As imagens abaixo permitem visualizar um pouco do que seria esta outra forma de atuação.
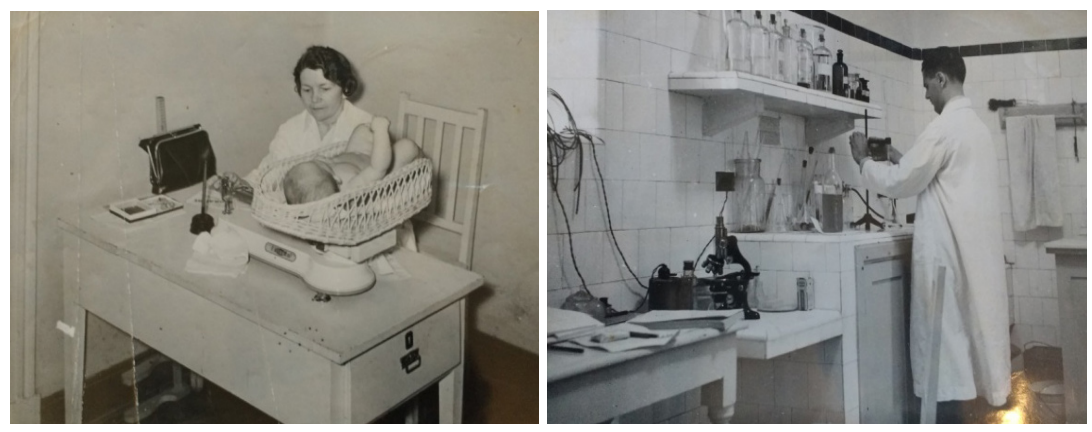

Imagens 7 e 8: Série 1. Fotografias. Tipo: 1.2. Adultos (em atuação em um laboratório e um consultório)

Fonte: Acervo cBL, s/d. Período provável: década de 1930).

Em texto produzido por Sanglard (2016) sobre o pediatra higienista Fernandes Figueira que teve grande atuação na assistência à infância do Rio de Janeiro no início do século xx, estabelece-se o diálogo com as imagens destacadas. Ao abordar a importância da criação de consultórios para lactantes, o médico defendia que o local seria de simples instalações, com baixo custo e que, portanto, poderia ser multiplicado em vários pontos da cidade. Bastava que houvesse "uma sala, um médico, um mobiliário pobre, a balança, e o microscópio com os seus acessórios" (Sanglard, 2016, p. 59).

Nas fotografías obtidas na creche Baroneza de Limeira, aparecem os elementos do consultório médico descrito por Figueira. Na primeira imagem, a pesagem de um bebê é registrada para demonstrar uma das ações principais do atendimento que se relaciona com a questão da alimentação e ganho de peso do bebê. Não é o médico quem o faz. Pelos registros da creche, poderia ser uma assistente, uma das senhoras da alta sociedade que atuavam como colaboradoras no local. Já a imagem seguinte é dotada não somente dos utensílios simples, mas de vidraria que indica que o consultório era útil também como um laboratório de análises. Ambas as pessoas parecem estar uniformizadas e as fotos parecem ter sido tiradas para demonstrar a atuação da policlínica no período. Também é importante ressaltar que não se sabe se as fotografias foram tiradas no mesmo dia ou até mesmo no mesmo local, já que não há registros sobre a produção das mesmas. Elas se encontram no mesmo álbum de fotos, onde há um registro escrito à mão do endereço da creche (Rua Vergueiro, 301) que seria sua instalação entre as décadas de 1920 a 1940. 
A educação de jovens mães seria realizada também nos consultórios, com orientações originárias dos estudos da puericultura e, na imagem abaixo, também se pode pensar que a policlínica que a princípio localizava-se junto à creche, prestava este tipo de serviço à população.

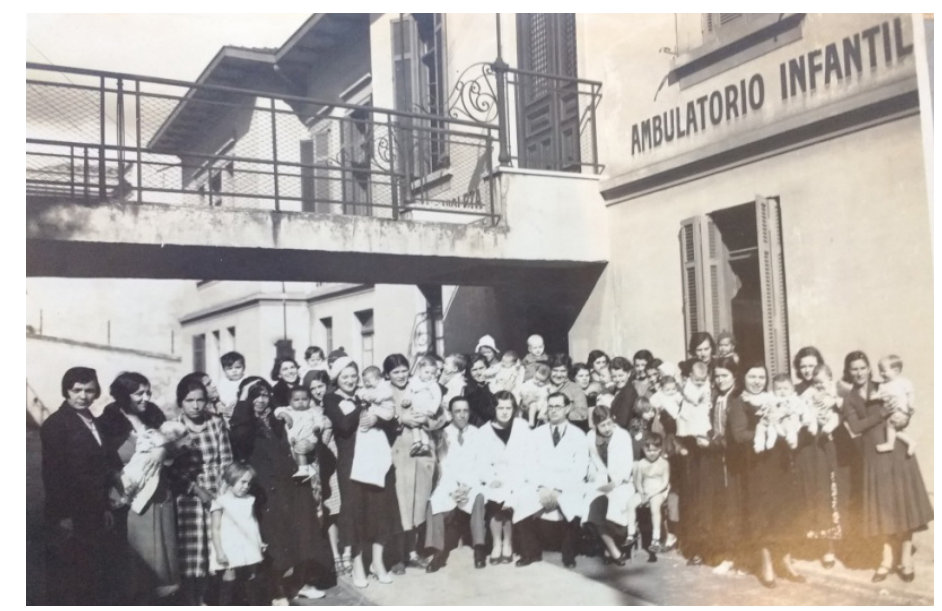

Imagem 9: Série 1. Fotografias. Tipo: 1.2. Adultos posando com os bebês em frente ao ambulatório infantil

Fonte: Acervo cBL, s/d. Período provável: década de 1930.

No primeiro contato com a fotografia, perguntavámos sobre as identidades das pessoas da imagem: mães, funcionárias da creche, senhoras da sociedade que contribuíam para o funcionamento do local? Contudo, a partir da referência teórica que destaca que um dos focos de atuação das clínicas e laboratórios de atendimento infantil seria a orientação às mães com relação aos cuidados de seus bebês, e analizando o vestuário das pessoas, mulheres com seus vestidos compridos, chapéus, bebês com vestimentas diversas e não uniformizadas, como ocorria com as crianças que residiam na creche, é provável que se trate de uma fotografia que retrata um dia de atendimento dos bebês e suas mães, denotando que o trabalho da creche, juntamente com o conjunto de serviços ofertados pela policlínica e "gotta de leite" tinham por preceito educar não somente as crianças mas, também, as mães destas crianças.

A sincronia das práticas da Creche Baroneza de Limeira com os discursos científicos que circulavam no período indica que a creche seria um modelo exemplar da época: a materialização do saber médico, unido à filantropia desenvolvida pelas classes sociais abastadas, buscando um ideal social e uma urbanidade, sinônimos de desenvolvimento. 
As crianças atendidas, por sua vez, poderiam ser salvas das doenças, do abandono e da miséria. Roupas claras, seguindo um mesmo padrão, cabelos cortados, corpos saudáveis, bem alimentados são destaques de seu acervo iconográfico. Em outro conjunto de imagens, as crianças são apresentadas sozinhas.

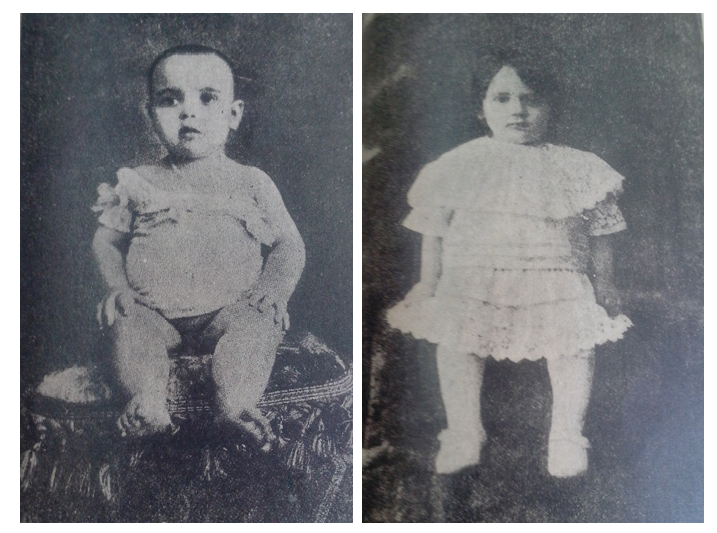

Imagens 11 e 12: Série 1. Fotografias. Tipo: 1.1. Crianças

Fonte: Acervo CBL, Relatório de Atendimento de 1915 a 1920

As fotografias destacam os bebês prontos para serem fotografados, sentados em tamboretes; no caso da primeira foto a robustez da criança, bem como sua pose de preparação para a fotografia é que se destaca. Entretanto uma atenção especial à fotografia nos mostra que o bebê está com roupinhas de calor, e uma espécie de colar cruz, Em função do caráter religioso da instituição após a chegada das irmãs da Congregação da Imaculada Conceição em 1915 e a forte presença católica na sociedade paulista do período, tal colar não apenas representa pertencimento à comunidade cristã, mas parece ressaltar a situação de cuidado e proteção divina ao bebê. Já a segunda imagem nos mostra uma criança paramentada com um vestido de rendas e babados, com sapatos e meias longas, cabelo penteado. Curiosamente, em ambas as imagens, o fato de as crianças estarem no centro da fotografia, com roupas claras, sobre um fundo escuro, dão a elas não apenas o foco da foto, mas também a importância de ressaltarem-se suas compleições físicas, seus atributos de crescimento. As imagens são destaque do relatório de atendimento da creche no período que compreende os anos de 1915 a 1920 e, portanto, as fotografias foram produzidas com a finalidade de demonstrar às sócias contribuintes, pessoas simpatizantes à causa, líderes sociais que contribuíam com doações à creche, a eficácia do trabalho da creche. 
As fotografias de crianças brincando também emergem no acervo de imagens da década de 1930, indicando uma concepção de criança que está para além de seus cuidados físicos. O trabalho da creche, já com vários anos de experiência havia demonstrado à sociedade sua eficácia e necessidade de existência, e, agora, já poderia olhar para outras características da infância que ali já estaria protegida. A palavra "recreio" como sinônimo de espaço e horário para brincar aparece pela primeira vez no relatório em 1931, como sendo parte de um horário específico, em local isolado e amplo.

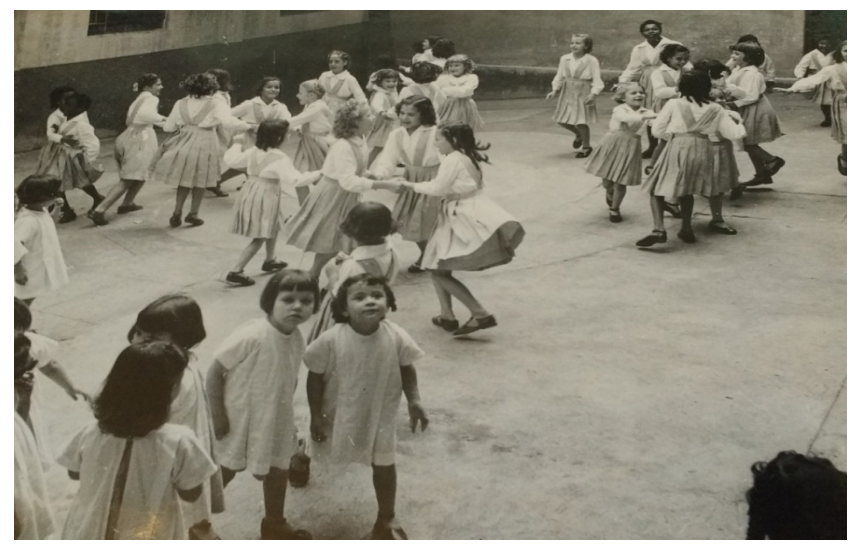

Imagem 13: Série 1. Fotografias. Tipo: 1.1. Crianças brincando em área externa. Fonte: Acervo CBL, s/d. Período provável: década de 1930

O recreio aparece enquanto prescrição compondo o quadro de horários das atividades escolares na segunda década do século xx. Na creche, entretanto, como as condições de abandono das crianças acabavam por tornar a instituição um espaço educativo para crianças maiores, percebemos não apenas a existência de práticas como as de recreios, concebidas pra crianças de todas as idades, mas também a presença de diferentes vestimentas que as diferenciavam.

$\mathrm{Na}$ fotografia, as crianças maiores, todas meninas, brincam de roda. Apesar de parecer uma atividade livre, a composição da brincadeira na imagem indica certa organização e orientação com relação àquele momento, pois há quatro grupos formando quatro rodas separadas, com quatro ou cinco crianças em cada uma delas. Quem brinca de roda na fotografia são as maiores, enquanto as meninas menores parecem observar e, inclusive demonstram curiosidade ao olhar diretamente para quem está tirando a fotografia. Percebe-se que estas pequenas usam vestidos soltos, confortáveis e com abertura traseira, como aventais hospitalares, sem a preocupação em cobrir tanto seus corpos. Parece ser o conforto e 
a facilidade para vestir ou retirar a roupa, assim como a possiblidade de tratar delas higienicamente, que dão o tom do atendimento àqueles corpos infantis. Já as maiores, ostentam uniformes de modelo escolar, inclusive com camisas de mangas cumpridas e saias com pregas.

Com relação ao atendimento exclusivamente feminino, o relatório de 1927-1931 apresenta uma modificação no atendimento da creche. Originalmente recebendo bebês de ambos os sexos, a questão do abandono de crianças na instituição, fazendo com que a mesma se tornasse uma espécie de orfanato onde as crianças acabavam por permanecer até a idade escolar, fez com que a diretoria optasse por receber somente crianças do sexo feminino, pois assim, poderia instalar também uma escola adequada ao ensino daquilo que seria próprio para as mulheres da época. Nesse sentido, há a indicação da chegada da normalista D. Emma de Sá Rocha para dar aulas às órfãs, que chegavam ao número de 80 . As meninas matriculadas teriam seu tempo dividido entre afazeres domésticos e estudos. Uma das irmãs de caridade daria aulas de trabalho de agulhas e, teriam ainda aulas de ginástica.

\section{Considerações Finais}

A materialidade da Creche Baroneza de Limeira tem configurado um rico material histórico para pensarmos a institucionalização das creches no Brasil. A complexidade desse ambiente de atendimento infantil é congruente à multiplicidade de fenômenos políticos e sociais emergentes no início do século xx. Em seu interior, a preocupação em salvar as crianças da fome, da miséria e das doenças cria ações pontuais de cuidado e assistência. Ao mesmo tempo, o caráter institucional de sua documentação também converge com alguns aspectos peculiares do universo da cultura escolar, como por exemplo, seus livros de matrícula, com informações sobre a criança, número de matrícula e paginação, tipografia própria.

Além disso, o controle dos corpos, as orientações médicas e a preocupação em publicizar seu trabalho e legitimar-se como espaço de atendimento à infância, favorecem a crença de que as crianças ali atendidas estariam em melhores condições do que aquelas providas por suas famílias de origem, impulsionando uma representação da creche como instituição social, de assistência e também de educação, essencial para aquela sociedade.

Há um discurso recorrente que separa educação e assistência muito em função dos documentos prescritivos e da legislação. No entanto, quando adentramos nos espaços onde ocorriam as práticas de atendimento à infância, o acesso às fontes permite perceber que não há tanta linearidade, tampouco rupturas bruscas nas práticas e representações historicamente construídas entre a educação como forma de intervenção cultural nestas

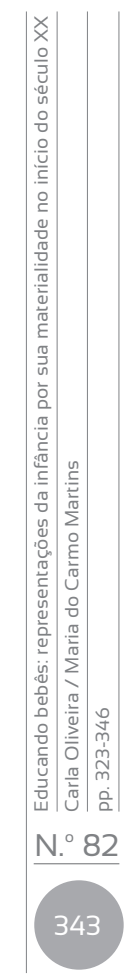


crianças e seus familiares e, a assistência, como prática social. Assim, analisar o conjunto de elementos, tanto da vida na creche, quanto da creche na vida da cidade, revela uma nova perspectiva nos estudos sobre a história da educação infantil e da infância.

Dona Paulina de Souza Queiróz faleceu em 1936, deixando um legado perene de seu trabalho. Em seu testamento deixou grande parte de sua fortuna à instituição, e solicitou que a administração futura ficasse em poder de seus familiares. Seu pedido e herança permitiu que, nos anos 50 um novo prédio fosse construído, onde encontra-se a atual instalação da creche. A administração familiar não impediu que a creche se atualizasse em sincronicidade às mudanças políticas e sociais de cada período e, hoje, a creche vincula-se, por meio de convênio, à Secretaria de Educação Municipal da cidade de São Paulo, atendendo crianças entre zero a cinco anos.

A pesquisa a partir das fontes encontradas permitem a reflexão sobre os processos históricos que sedimentaram o trabalho nas creches no Brasil. A inserção da mulher no mundo do trabalho foi, seguramente, uma condição histórica para que se começasse a pensar na importância desta instituição. Os problemas sociais em um cenário de expansão das grandes cidades, a pobreza e o entendimento que as crianças deveriam ser cuidadas em consonância com o ideário nacional, fizeram com que a creche tivesse, em suas origens, um caráter muito mais voltada à infância desvalida, porém já se configura alí, um conjunto de práticas educativas que visa o abrigo à infância. O aparato material utilizado para cuidar das crianças aponta para um viés pautado nas questões higienistas e naquilo que os grupos sociais mais enriquecidos e empoderados da época acreditavam ser importante para ordenar a sociedade. Na creche percebe-se a predominância dos elementos estéticos que estivessem em consonância com a ordem, a limpeza, a organização dos espaços. Predominam as representações de uma infância saudável e concebida como uma etapa especial ao longo de uma vida.

Aos poucos as mudanças políticas e sociais favorecem a creche como uma instituição de atendimento à infância que deveria se diferenciar dos abrigos, o que vai fazendo dela, finalmente, um local de atendimento aos filhos das mulheres, trabalhadoras pobres ou de classe média, o que vai ocorrer somente nas décadas finais do século xx, encontrando seu aparato legal na LDB de 1996.

Decorrido mais de um século de sua construção histórica, as creches no Brasil atual ocupam outro lugar como ambiente educativo não mais meramente assistencial, voltada às crianças desvalidas. Sua história, entrentanto, nos remete ao fato de que práticas e representações não são alteradas a partir da promulgação de leis, mas sobrevivem em meio a 
mudanças e permanências, o que nos permite refletir sobre a importância da história para a compreensão das instituições sociais, muitas vezes tão naturalizadas.

Por fim, pensar em uma história atuação da creche, é pensar que, apesar das mudanças de concepções de trabalho e de práticas ao longo de pouco mais de 100 anos, está a ideia de uma criança que sai do âmbito familiar e passa a ser cuidada, educada e constituída em outras instâncias e instituições sociais. Desta forma é que podemos apontar a configuração de uma criança que assume um lugar social próprio: sujeito para o qual uma materilidade específica passa a ser fabricada e comercializada, ao mesmo tempo em que a responsabilidade por seu desenvolvimento, desde a mais tenra idade ocupa sujeitos diversos que negociam, à partir de seus saberes próprios, a representação do que deve ser uma instituição voltada à educação não familiar dos bebês.

\section{Referências}

Bosi, M. L. M. e Machado, M. T. (2005). Amamentação: um resgate histórico. Cadernos ESP - Escola de Saúde Pública do Ceará, 1(1). http://www. aleitamento.com.br/upload\%5Carquivos\%5Carquivo1_1688.pdf

Burke, P. (2004). Testemunha Ocular. Bauru, EDusC.

Chalhoub, S. (1986). Trabalho, Lar e Botequim: O Cotidiano dos Trabalhadores no Rio de Janeiro da Belle Époque. Brasiliense.

Escolano, A. (2017) A escola como cultura: Experiência, memória e arqueologia. Alínea.

Freire, M. M. L. (2016). Salvando o esteio da nação: Moncorvo Filho e o Instituto de Proteção à Assistência à Infância no Rio de Janeiro. Em G. Sanglard (org.), Amamentação e políticas para a infância no Brasil: A atuação de Fernandes Figueira, 1902 - 1928. Fio Cruz.

Gaspar da Silva, V. L. G. e Souza, G. (2015) Percursos e recursos de uma experiência formativa em pesquisa sobre cultura material escolar. Em Souza, R. F.; Pinheiro, A. C. F. e Lopes, A. P. C. (orgs.), História da escola primária no Brasil - investigação em perspectiva comprada em âmbito nacional (pp. 471-488). Edise.

Kuhlmann Jr. M. (2000). Educando a infância brasileira. Em E. M. Teixeira, L. M Faria Filho, C. G Veiga (orgs.), 500 anos de educação no Brasil ( $2^{\circ}$ edição), (pp. 469-496). Belo Horizonte.

Kuhlmann Jr. M. (2001). O jardim de infância e a educação das crianças pobres: Final do século xIx, início do século xx. Em C. Monarcha (Org.), Educação da infância brasileira: 1875-1983. Autores Associados.

Le Goff, J. (1990). História e Memória. Editora da Unicamp. 
Oliveira, C. (2014). Mulheres cuidadoras, mulheres professoras: história, memória e formação profissional na Creche Área de Saúde da Unicamp (Dissertação). Faculdade de Educação da Unicamp - Campinas, São Palo, Brasil. http://repositorio.unicamp.br/bitstream/REPOSIP/254156/1/Oliveira_Carlade_M.pdf

Sanglard, G. (2016). Fernandes Figueira e a política de assistência à infância: Estado, Filantropia e aleitamento materno. Em G. Sanglard (org.), Amamentação e políticas para a infância no Brasil: A atuação de Fernandes Figueira, 1902-1928 (Cap. 2). Fio Cruz.

Seade. (1896, jan). Boletim Mensal de Estatistica Demographo-Sanitaria, 3(1). https://bibliotecadigital.seade.gov.br/view/listarPublicacao. php?lista $=0 \&$ opcao $=8 \&$ busca $=1 \&$ tipoFiltro=periodo \&filtro $=\% 271896 \% 27 \&$ descFiltro $=1896 \&$ listarConteudo $=$ Cole $\%$ C3\%A7\%C3\%B5es\%20\%C2\%BB\%20Anu\%C3\%A1 rio\%20de\%20 Estat\%C3\%ADstica\%20Dem\%C3\%B3grafo-Sanit\%C3\%A1 ria

Vidal, D. G. e Gaspar da Silva, V. L. G. (2010). Por uma história sensorial da escola e da escolarização. Revista Linhas, 11(2), 29-45. http:// www.revistas.udesc.br/index.php/linhas/article/view/2127 